European

Thyroid Journal
Eur Thyroid J 2019;8:246-255

DOI: $10.1159 / 000500539$
Received: November 27, 2018

Accepted after revision: April 16, 2019

Published online: June 26, 2019

\title{
Risk of Thyroid Cancer in 1,504 Patients Referred for Thyroid Surgery with Assumed Benign Histology
}

\author{
Signe Buhl Gram ${ }^{a}$ Jacob Høygaard Rasmussen ${ }^{a} \quad$ Ulla Feldt- \\ Rasmussen $^{\mathrm{b}}$ Jens Bentzen ${ }^{c}$ Giedrius Lelkaitis ${ }^{\mathrm{d}}$ Christian von Buchwald ${ }^{\mathrm{a}}$ \\ Christoffer Holst Hahn ${ }^{a}$ \\ ${ }^{a}$ Department of Otorhinolaryngology, Head and Neck Surgery and Audiology, Rigshospitalet, Copenhagen \\ University, Copenhagen, Denmark; ${ }^{\mathrm{b}}$ Department of Medical Endocrinology, Rigshospitalet, Copenhagen University, \\ Copenhagen, Denmark; ' Department of Oncology, Herlev Hospital, Copenhagen University, Copenhagen, \\ Denmark; ${ }^{d}$ Department of Pathology, Rigshospitalet, Copenhagen University, Copenhagen, Denmark
}

\section{Keywords}

Fine-needle aspiration · Thyroid cancer · Thyroid cytology ·

Benign lesion · Thyroid surgery

\begin{abstract}
Objectives: The aims of this study were to report the risk of thyroid malignancy in cases of either benign fine-needle aspiration (FNA) or without FNA performed, and to investigate possible predictive factors for thyroid malignancy in a population with recent moderately low iodine intake. Methods: All patients referred for thyroid surgery in a tertiary cancer centre between 2000 and 2016 were included $(n=3,703)$. After excluding cases indicating malignant histology, we included group 1: patients with benign FNA $(n=764)$, and group 2: patients without FNA $(n=740)$, leaving 1,504 eligible for further investigation. Information on age, gender, tracheal compression or dislocation, thyroid specimen weight, scintigraphy, ultrasound, medically treated thyrotoxicosis, serum stimulating thyroid hormone, indication for surgery, TNM classification, stage, and outcome were retrieved. Results: The malignancy risk was $7.6 \%(58 / 764)$ in group 1 and $6.8 \%(50 / 740)$ in group 2 . Patients with T2-4 tumours constituted $2.2 \%(33 / 1,504)$. In the combined groups, ultrasound
\end{abstract}

verified that solitary solid tumour was predictive for malignancy $\left(p=0.01\right.$ by $X^{2}$, and $O R=1.69, p=0.02$ in multiple logistic regression). For group 1 patients, thyrotoxicosis (which in this case was medically treated) was a significant predictive factor for malignancy $(p=0.04)$. Conclusions: The risk of malignancy of $7.6 \%$ and $6.8 \%$ was high, considering that patients with malignant FNA, suspicious FNA, or clinical findings indicating malignancy were excluded, and $2.2 \%$ of these malignancies were stages $\mathrm{T} 2-4$. In cases with solitary solid tumour on ultrasound, the risk of malignancy should not be ignored, even with benign FNA.

\footnotetext{
(C) 2019 European Thyroid Association Published by S. Karger AG, Basel
}

\section{Introduction}

Thyroid carcinoma is the most common endocrine malignancy. Two Danish studies report an incidence of 1.57 cases per 100,000 men, 4.11 cases per 100,000 women [1], and 4.5 cases per 100,000 men and women [2]. With a rapidly growing incidence - caused almost exclusively by low-mortality papillary tumours - accurate diagnostic methods become increasingly important in order to deal

\section{KARGER}

(C) 2019 European Thyroid Association

Published by S. Karger AG, Basel
Signe Buhl Gram

Department of Otorhinolaryngology, Head and Neck Surgery and Audiology Rigshospitalet, Copenhagen University, F2073, Blegdamsvej 9 DK-Copenhagen 2100 (Denmark)

E-Mail signe.buhl.gram.01@ regionh.dk 
Fig. 1. Study population. FNA, fine-needle aspiration; THYRKIR, the Danish Thyroid Surgery Database.

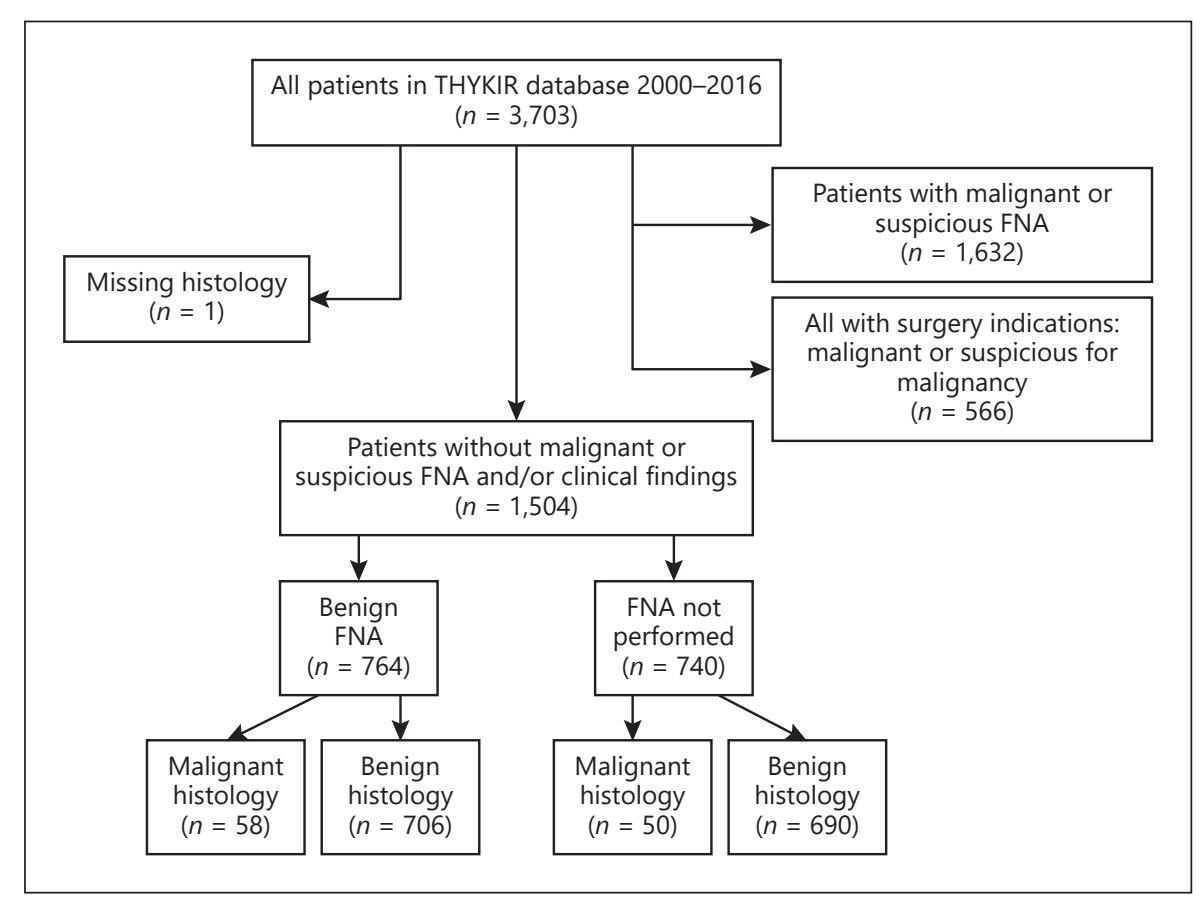

with the growing number of patients $[3,4]$. Preoperative assessment of thyroid nodules, however, remains a diagnostic challenge. In Denmark, scintigraphy and ultrasound are performed as part of the investigation in which cold nodules on scintigraphy and suspicious nodules on ultrasound are further investigated with fine-needle aspiration (FNA) [5]. Accurate FNA cytology diagnosis is dependent upon a number of factors including the skills of the operator, FNA techniques, specimen preparation, and cytology interpretation, altogether affecting the false-negative rate of benign cytology diagnosis [6-8]. Another diagnostic problem concerns patients with thyrotoxicosis or multinodular goitre without a cold nodule by scintigraphy, in which case FNA is not performed due to low risk of malignancy or because the patient will be referred to surgery for hyperthyroidism regardless.

Two autopsy studies concluded that the prevalence of occult papillary carcinoma in the thyroid was between 11 and $36 \%[9,10]$, and 2 recent studies suggested observation rather than surgery in papillary microcarcinomas (PMC) $[11,12]$. Taking this into account, it should be considered when a preoperative diagnosis is relevant. Non-lethal PMC might not affect the management or treatment of the patient. Nevertheless, a preoperative diagnosis of thyroid cancer is important in order to avoid delay in surgery. Regarding patients with clinical thyroid carcinomas, avoiding reoperation, recurrence, metastasis, and death is important.
This study advances present knowledge by investigating the fate of patients with missed preoperative cancer diagnosis. Our aims were (1) to report the risk of malignancy in cases referred for surgery either with benign FNA or without FNA and identify possible predictive risk factors of malignancy in a population with recent moderately low iodine intake, and (2) to investigate the TNM classification and assess the outcome in patients with stages T2-4.

\section{Materials and Methods}

\section{Investigation}

All patients who had thyroid surgery performed at the Department of Otorhinolaryngology, Head and Neck Surgery and Audiology, Rigshospitalet University of Copenhagen, between 2000 and 2016 were investigated according to guidelines from the Danish Endocrine Society (DES). Eighty percent of the patients were referred from endocrinology departments.

If patients had a fast-growing nodule or paresis of the recurrent laryngeal nerve, they were admitted to a fast-track program; otherwise a further investigation of thyroid stimulating hormone (TSH) was performed. Normal TSH resulted in subsequent investigation with ultrasound and scintigraphy. FNA, which is always guided by ultrasound in Denmark, was performed in cases with a suspicious nodule on ultrasound, or if scintigraphy revealed a cold solitary nodule or a multinodular goitre with a dominant cold nodule. Hot nodule, multinodular goitre without a dominant cold area, or toxic thyroid nodules are usually not investigated with FNA [5]. Consultant pathologists performed the pathological investigation in this study. 


\section{Included Patients}

All patients who had thyroid surgery performed were identified from the prospectively registered database, the Danish Thyroid Surgery Database (THYKIR), and were evaluated concerning histological diagnosis.

Only patients referred for thyroid surgery and with benign clinical findings and benign FNA, corresponding to The Bethesda group II, or patients with no FNA performed were included in this study. All patients in the group with benign FNA had a nodule, but the patients without FNA performed did not necessarily have any.

All patients who underwent surgery would generally have a preceding FNA performed. However, in our current study, 740 patients with no preceding FNA underwent surgery. This was a consequence of either thyrotoxicosis or pressure symptoms combined with a multinodular goitre without a cold nodule on scintigraphy.

\section{TNM Classification, Stage, and Outcome}

In this study, data on TNM classification and stage of the thyroid malignancies and outcome for patients with T2-4 were retrieved from DATHYRCA and The Danish Pathology Registry. The DATHYRCA database is contained within the Danish Head and Neck Cancer study group (DAHANCA), which prospectively registers clinical, surgical, histopathological, and follow-up data from Danish thyroid cancer patients nationwide. The Danish Pathology Registry is a national database that includes all histological and cytological reports in Denmark, and in the current study six or seven pathologists were involved.

\section{Statistics}

The correlation between age, gender, tracheal compression or dislocation, scintigraphy, ultrasound, TSH, distribution of malignant histology, and patients with thyrotoxicosis (which in this case was medically treated), were tested with $\chi^{2}$ or Fisher's exact test. The Mann-Whitney U test was used to determine the total weight of the surgically removed thyroid specimen. Ultrasound and scintigraphy were dichotomized and a $p$ value $<0.05$ was considered significant. Ultrasound, scintigraphy, and gender were further included in multiple logistic regressions. All statistical analyses were performed in IBM SPSS Statistics 22.

\section{Results}

\section{Inclusion, Exclusion, and Patient Characteristics}

Rigshospitalet manages the treatment of thyroid cancers in Eastern Denmark, which has a population of 2.6 million people. Rigshospitalet attends to 1.2 million of this population with specific regard to benign thyroid surgery. In total, 3,703 patients, referred for thyroid surgery, were included in this study, and 1,504 were eligible for further analysis after excluding patients with malignant FNA, suspicious FNA, and clinical findings indicating malignancy. Figure 1 depicts a consort diagram of patient inclusion and exclusion. Table 1 shows patient characteristics. The patients were divided into group 1: with benign FNA ( $n=764)$, and group 2: where FNA was not performed $(n=740)$. Tables 2 and 3 show the patient characteristics of these two groups. We retrieved and evaluated clinical information concerning histological diagnosis, age, gender, tracheal compression or dislocation, total weight of surgically removed thyroid specimen, scintigraphy, ultrasound, serum TSH, indication for surgery, TNM classification, stage, outcome and thyrotoxicosis (in this case medically treated or not). Patients with malignant histological diagnosis constituted $7.6 \%(58 / 764)$ of group 1 and $6.8 \%$ of group $2(50 / 740)$.

\section{Histological Diagnoses}

Table 4 depicts the distribution of malignant histological diagnoses in the whole study population $(\mathrm{n}=$ 3,703 ) and specifically within the two groups concerned. There was no statistical difference in the distribution of malignancy types between the two groups compared to the whole study population. In group $1,79.3 \%$ of the malignant tumours $(n=58)$ were diagnosed as papillary carcinoma, $12.1 \%$ as follicular carcinoma, $3.5 \%$ as medullary carcinoma, $1.7 \%$ as undifferentiated carcinoma, and $3.4 \%$ as other types of malignancy. Correspondingly, $62.0 \%$ of the malignant tumours $(n=50)$ in group 2 were diagnosed as papillary carcinoma, $14.0 \%$ as follicular carcinoma, $4.0 \%$ as medullary carcinoma, $6 \%$ as undifferentiated carcinoma, and $14 \%$ as other malignancies.

\section{Predictive Factors for Malignancy}

A number of variables were analysed to identify possible predictive factors for malignancy, the results of which are presented in Tables 1-3 and Table 5. The presence of a solitary solid tumour assessed by ultrasound was a significant predictor for malignancy $(p=0.01)$ in the 1,504 patients with benign FNA or no FNA performed. For group 1 patients, thyrotoxicosis (which in this case was medically treated) was a significant predictive factor for malignancy $(p=0.04)$. Multiple logistic regression analyses determined solitary solid tumour on ultrasound to be a significant predictor for malignancy $(\mathrm{OR}=1.69, p=0.02)$.

\section{Surgery Indication}

The indication for surgery was evaluated and the results are presented in Table 6. Generally, the typical patient with FNA performed had pressure symptoms or a nodule, and the patients without FNA performed had thyrotoxicosis or pressure symptoms and a multinodular goitre without dominant cold areas. Pressure symptoms, 
Table 1. Factors possibly predictive of malignancy among patients with both a benign FNA and without FNA performed

\begin{tabular}{|c|c|c|c|c|c|}
\hline & \multicolumn{2}{|c|}{ Malignant histology } & \multicolumn{2}{|c|}{ Benign histology } & \multirow[t]{2}{*}{$p$ value } \\
\hline & $n$ & $\%^{\mathrm{a}}$ & $n$ & $\%^{\mathrm{b}}$ & \\
\hline Total & 108 & 100 & 1,396 & 100 & \\
\hline \multicolumn{6}{|l|}{ Age } \\
\hline$<20$ years & 4 & 4 & 28 & 2 & \\
\hline$>70$ years & 12 & 11 & 159 & 11 & \\
\hline Sex & & & & & 0.69 \\
\hline Female & 89 & 82 & 1,128 & 81 & \\
\hline Male & 19 & 18 & 268 & 19 & \\
\hline Serum TSH & & & & & 0.62 \\
\hline Hypothyroid & 5 & 5 & 36 & 3 & \\
\hline Hyperthyroid & 16 & 15 & 233 & 17 & \\
\hline Euthyroid & 82 & 76 & 1,078 & 77 & \\
\hline Missing & 5 & 5 & 49 & 4 & \\
\hline Ultrasound finding & & & & & $0.01^{*}$ \\
\hline Solitary solid tumour & 37 & 34 & 333 & 24 & \\
\hline Other & 43 & 40 & 751 & 54 & \\
\hline Missing & 28 & 26 & 312 & 22 & \\
\hline Scintigraphic finding & & & & & 0.07 \\
\hline Cold nodule & 47 & 44 & 574 & 41 & \\
\hline Other & 35 & 32 & 626 & 45 & \\
\hline Missing & 26 & 24 & 196 & 14 & \\
\hline Compression of trachea & & & & & 0.49 \\
\hline No & 72 & 67 & 849 & 61 & \\
\hline Yes & 16 & 15 & 254 & 18 & \\
\hline Missing & 20 & 19 & 293 & 21 & \\
\hline Dislocation of trachea & & & & & 0.33 \\
\hline No & 70 & 65 & 812 & 58 & \\
\hline Yes & 19 & 18 & 313 & 22 & \\
\hline Missing & 19 & 18 & 271 & 19 & \\
\hline Medically treated thyrotoxicosis & & & & & 0.45 \\
\hline No & 77 & 71 & 894 & 64 & \\
\hline Yes & 20 & 19 & 282 & 20 & \\
\hline Missing & 11 & 10 & 220 & 16 & \\
\hline Weight ${ }^{c}$ & & & & & 0.90 \\
\hline Median & 39 & & 44 & & \\
\hline Minimum & 4 & & 0.4 & & \\
\hline Maximum & 360 & & 1,655 & & \\
\hline
\end{tabular}

FNA, fine-needle aspiration; TSH, thyroid stimulating hormone. ${ }^{\text {a }}$ Percent of predictive factor out of total number of patients with malignant histology $(n=108) .{ }^{\mathrm{b}}$ Percent of predictive factor out of total number of patients with benign histology $(n=1,396) .{ }^{c}$ Total weight of surgically removed thyroid specimen. ${ }^{*} p<0.05$, statistically significant.

thyrotoxicosis, or respiratory influence were not related to malignant or benign histology.

\section{TNM, Stage, and Outcome}

Table 7 depicts the TNM classification and Table 8 the stage of the thyroid malignancies. In Table 9 the outcome of patients with T2-4 malignancies is presented. In group 1, most thyroid malignancies were T1 (56.9\%, $n=33)$ and stage I $(75.9 \%, n=44)$ and the remaining malignancies were classified as T2 $(15.5 \%, n=$ 9), T3 $(15.5 \%, n=9)$, and T4 $(3.4 \%, n=2)$, and stage II $(6.9 \%, n=4)$, III $(3.4 \%, n=2)$, and IV $(5.2 \%, n=3)$. 
Table 2. Factors possibly predictive of malignancy among patients with a benign FNA

\begin{tabular}{|c|c|c|c|c|c|}
\hline & \multicolumn{2}{|c|}{ Malignant histology } & \multicolumn{2}{|c|}{ Benign histology } & \multirow[t]{2}{*}{$p$ value } \\
\hline & $n$ & $\%^{\mathrm{a}}$ & $n$ & $\%^{\mathrm{b}}$ & \\
\hline Total & 58 & 100 & 706 & 100 & \\
\hline \multicolumn{6}{|l|}{ Age } \\
\hline$<20$ years & 3 & 5 & 10 & 1 & \\
\hline$>70$ years & 4 & 7 & 53 & 8 & \\
\hline Sex & & & & & 0.55 \\
\hline Female & 46 & 79 & 582 & 82 & \\
\hline Male & 12 & 21 & 124 & 18 & \\
\hline Serum TSH & & & & & 0.34 \\
\hline Hypothyroid & 1 & 2 & 14 & 2 & \\
\hline Hyperthyroid & 4 & 7 & 19 & 3 & \\
\hline Euthyroid & 52 & 90 & 664 & 94 & \\
\hline Missing & 1 & 2 & 9 & 1 & \\
\hline Ultrasound finding & & & & & 0.06 \\
\hline Solitary solid tumour & 30 & 52 & 410 & 58 & \\
\hline Other & 28 & 48 & 265 & 38 & \\
\hline Missing & 0 & & 31 & 4 & \\
\hline Scintigraphic finding & & & & & 0.19 \\
\hline Cold nodule & 44 & 76 & 472 & 67 & \\
\hline Other & 11 & 19 & 186 & 26 & \\
\hline Missing & 3 & 5 & 48 & 7 & \\
\hline Compression of trachea & & & & & 0.22 \\
\hline No & 44 & 76 & 468 & 66 & \\
\hline Yes & 4 & 7 & 90 & 13 & \\
\hline Missing & 10 & 17 & 148 & 21 & \\
\hline Dislocation of trachea & & & & & 0.07 \\
\hline No & 42 & 72 & 423 & 60 & \\
\hline Yes & 7 & 12 & 146 & 21 & \\
\hline Missing & 9 & 16 & 137 & 19 & \\
\hline Medically treated thyrotoxicosis & & & & & $0.04^{*}$ \\
\hline No & 48 & 83 & 561 & 79 & \\
\hline Yes & 5 & 9 & 19 & 3 & \\
\hline Missing & 5 & 9 & 126 & 18 & \\
\hline Weight ${ }^{c}$ & & & & & 0.23 \\
\hline Median & 38 & & 33 & & \\
\hline Minimum & 4 & & 2 & & \\
\hline Maximum & 360 & & 1,655 & & \\
\hline $\begin{array}{l}\text { FNA, fine-needle aspiration, } \\
\text { number of patients with maligna } \\
\text { number of patients with benign } h \\
\text { specimen. }{ }^{*} p<0.05 \text {, statistically }\end{array}$ & $\begin{array}{l}\text { thyro } \\
\text { ology } \\
\text { y anc } \\
\text { cant. }\end{array}$ & $\begin{array}{l}\text { lating h } \\
\text { ign FN } \\
\text { FNA }(n\end{array}$ & $\begin{array}{l}\text { a Perce } \\
\text { ) }{ }^{\text {b Perc }} \\
\text { Total w }\end{array}$ & $\begin{array}{l}\text { oredic } \\
\text { predi } \\
\text { f surg }\end{array}$ & $\begin{array}{l}\text { out of } t \\
\text { out of } t \\
\text { oved thy }\end{array}$ \\
\hline
\end{tabular}

Similarly, in group 2, most malignancies were T1 (56\%, $n=28)$ and stage I $(54 \%, n=27)$ and the rest were classified as T2 $(10 \%, n=5), \mathrm{T} 3(6 \%, n=3)$, and T4 $(10 \%$, $n=5)$, and stages II $(8 \%, n=4)$, III $(6 \%, n=3)$, and IV $(14 \%, n=7)$. Patients with T2-4 accounted for $2.2 \%$ in total $(33 / 1504)$, and the outcome of these patients showed that 23 patients $(76.7 \%)$ were alive, 5 patients (16.7\%) had reoperation, 1 patient $(3.3 \%)$ had recurrence, and 4 patients $(12.1 \%)$ were dead ( 3 from undifferentiated thyroid carcinoma and 1 from an aortic aneurism). 
Table 3. Factors possibly predictive of malignancy among patients without FNA performed

\begin{tabular}{|c|c|c|c|c|c|}
\hline & \multicolumn{2}{|c|}{ Malignant histology } & \multicolumn{2}{|c|}{ Benign histology } & \multirow[t]{2}{*}{$p$ value } \\
\hline & $n$ & $\%^{\mathrm{a}}$ & $n$ & $\%^{\mathrm{b}}$ & \\
\hline Total & 50 & 100 & 690 & 100 & \\
\hline \multicolumn{6}{|l|}{ Age } \\
\hline$<20$ years & 1 & 2 & 18 & 3 & \\
\hline$>70$ years & 8 & 16 & 106 & 15 & \\
\hline Sex & & & & & 0.24 \\
\hline Female & 43 & 86 & 546 & 79 & \\
\hline Male & 7 & 14 & 144 & 21 & \\
\hline Serum TSH & & & & & 0.27 \\
\hline Hypothyroid & 4 & 8 & 22 & 3 & \\
\hline Hyperthyroid & 12 & 24 & 214 & 31 & \\
\hline Euthyroid & 30 & 60 & 414 & 60 & \\
\hline Missing & 4 & 8 & 40 & 6 & \\
\hline Ultrasound finding & & & & & 0.07 \\
\hline Solitary solid tumour & 7 & 14 & 68 & 10 & \\
\hline Other & 15 & 30 & 341 & 49 & \\
\hline Missing & 28 & 56 & 281 & 41 & \\
\hline Scintigraphic finding & & & & & 0.23 \\
\hline Cold nodule & 3 & 6 & 102 & 15 & \\
\hline Other & 24 & 48 & 440 & 64 & \\
\hline Missing & 23 & 46 & 148 & 21 & \\
\hline Compression of trachea & & & & & 0.99 \\
\hline No & 28 & 56 & 381 & 55 & \\
\hline Yes & 12 & 24 & 164 & 24 & \\
\hline Missing & 10 & 20 & 145 & 21 & \\
\hline Dislocation of trachea & & & & & 0.87 \\
\hline No & 28 & 56 & 389 & 56 & \\
\hline Yes & 12 & 24 & 167 & 24 & \\
\hline Missing & 10 & 20 & 134 & 19 & \\
\hline Medically treated thyrotoxicosis & & & & & 0.20 \\
\hline No & 29 & 58 & 333 & 48 & \\
\hline Yes & 15 & 30 & 263 & 38 & \\
\hline Missing & 6 & 12 & 94 & 14 & \\
\hline Weight ${ }^{c}$ & & & & & 0.13 \\
\hline median & 66 & & 63 & & \\
\hline minimum & 6 & & 0.4 & & \\
\hline maximum & 286 & & 907 & & \\
\hline
\end{tabular}

FNA, fine-needle aspiration; TSH, thyroid stimulating hormone. ${ }^{\text {a }}$ Percent of predictive factor out of total number of patients with malignant histology and no FNA performed $(n=50) .{ }^{\mathrm{b}}$ Percent of predictive factor out of total number of patients with benign histology and no FNA performed $(n=690){ }^{c}{ }^{\mathrm{c}}$ Total weight of surgically removed thyroid specimen. ${ }^{*} p<0.05$, statistically significant.

\section{Discussion}

As FNA is currently one of the triaging procedures in diagnosing thyroid malignancy, it is of great importance to investigate data on malignancy and possible predictive factors in cases of benign or no FNA. We found the risk of malignancy to be $7.6 \%$ in the group with benign FNA and $6.8 \%$ in the group without FNA. Whether the risk of malignancy is actually problematic can be discussed, since incidentalomas upon further inspection merely turn out to be predominantly non-lethal PMC [4], which might not affect the management 
Table 4. Distribution of malignant histological diagnoses among the total study population with malignant histology compared with malignant histological diagnoses in group 1 (benign FNA) and group 2 (without FNA)

\begin{tabular}{|c|c|c|c|c|c|c|c|c|}
\hline & \multicolumn{2}{|c|}{ All patients } & \multicolumn{2}{|c|}{ Benign FNA } & \multirow[t]{2}{*}{$p$ value* } & \multicolumn{2}{|c|}{ FNA not performed } & \multirow[t]{2}{*}{$p$ value ${ }^{* *}$} \\
\hline & $n$ & $\%$ & $n$ & $\%$ & & $n$ & $\%$ & \\
\hline Total & 793 & 100 & 58 & 100 & & 50 & 100 & \\
\hline Papillary carcinoma & 523 & 65.9 & 46 & 79.3 & 0.37 & 31 & 62.0 & 0.79 \\
\hline Follicular carcinoma & 145 & 18.3 & 7 & 12.1 & 0.31 & 7 & 14.0 & 0.52 \\
\hline Medullary carcinoma & 39 & 4.9 & 2 & 3.5 & 0.63 & 2 & 4.0 & 0.78 \\
\hline Undifferentiated carcinoma & 31 & 3.9 & 1 & 1.7 & 0.41 & 3 & 6.0 & 0.49 \\
\hline Other malignancy & 55 & 7 & 2 & 3.4 & 0.53 & 7 & 14.0 & 0.79 \\
\hline
\end{tabular}

FNA, fine needle aspiration. * The total study population with malignant histology vs. patients with benign FNA and malignant histology. ${ }^{* *}$ The total study population with malignant histology vs. patients without FNA and malignant histology.

and treatment of these patients. However, in the current study $2.2 \%(\mathrm{n}=33)$ of the patients had malignancies of stages T2, T3, and T4, and 9 of these experienced reoperation, recurrence, or death by thyroid cancer. Due to the unfavourable prognosis of these stages, it is essential to identify, diagnose, and adequately treat these patients. A correct preoperative diagnosis would improve outcome due to earlier and more comprehensive treatment.

This study is characterized by a high degree of referral and selection bias as the patients are from a cohort already referred for surgery, thus obscuring them from any other medical context.

In comparison to previously published studies on benign FNA, our results indicate a higher risk of malignancy: a review of 12 studies showed that of 4,055 patients with benign cytology who underwent surgery, 3.2\% (range 1.0-18.1\%) had a malignancy [13]. Furthermore, large retrospective series on the utility of repeated FNA in nodules with prior benign cytology results found a malignancy rate of only 1-2\% [14-16]. The high malignancy incidence in this study could have been due to differences in the indication for surgery or differences in the investigation of the patients, e.g., scintigraphy is standard procedure in Denmark as opposed to many other countries with a longer period of iodine sufficiency. The main reason for performing scintigraphy is the high prevalence of warm/hot nodules, particularly in multinodular goitres due to a moderately low iodine intake for more than half a century until the year 2000. If examined carefully, surgical specimens of these multinodular goitres might harbour low-mortality papillary tumours, thus contributing to a higher risk of malignancy.
Table 5. Multiple regression testing factors possibly predictive for malignancy among patients with both benign FNA and without FNA performed $(n=1,504)$

\begin{tabular}{llll}
\hline Variable & Odds ratio & $p$ value & $95 \%$ CI \\
\hline Sex & 0.89 & 0.66 & $0.52-1.53$ \\
Ultrasound finding & 1.69 & 0.02 & $1.09-2.61$ \\
Scintigraphic finding & 1.15 & 0.54 & $0.74-1.79$ \\
\hline
\end{tabular}

FNA, fine-needle aspiration.

Attempts have also been made to correlate higher malignancy with nodules greater than 3-4 cm $[17,18]$. Recent studies found that $10.4 \%$ of cytologically benign nodules $\geq 4 \mathrm{~cm}$ were malignant and $3.6 \%$ of cytologically benign nodules $>3 \mathrm{~cm}$ were malignant on postoperative histopathology $[19,20]$. This might be the cause of the high percentage of false-negative FNA in our study since it is Danish clinical procedure not to perform surgery in patients with a tumour $<4 \mathrm{~cm}$.

We found that $2.9 \%$ of the patients with a cold nodule on scintigraphy had no FNA performed. It might be otherwise expected that all cold nodules would result in FNA being performed. Probable explanations include intra-thoracic nodule and nodule inaccessible with FNA.

Surprisingly, $5.3 \%$ of the patients with no FNA had both thyrotoxicosis and malignant histological diagnosis, possibly due to that fact that many patients with Graves disease and thyrotoxicosis have a higher risk of small papillary foci by histology. Hyper-functioning thyroid carcinomas are generally rare, and to our knowledge only case 
Table 6. Surgery indication in patients grouped by histology, subgrouped by FNA (benign/without)

\begin{tabular}{|c|c|c|c|c|c|c|c|c|}
\hline & \multicolumn{4}{|c|}{ Malignant histology } & \multicolumn{4}{|c|}{ Benign histology } \\
\hline & \multicolumn{2}{|c|}{ benign FNA } & \multicolumn{2}{|c|}{$\begin{array}{l}\text { without FNA } \\
\text { performed }\end{array}$} & \multicolumn{2}{|c|}{ benign FNA } & \multicolumn{2}{|c|}{$\begin{array}{l}\text { without FNA } \\
\text { performed }\end{array}$} \\
\hline & $n$ & $\%$ & $n$ & $\%$ & $n$ & $\%$ & $n$ & $\%$ \\
\hline Total & 58 & 100 & 50 & 100.0 & 706 & 100.0 & 690 & 100.0 \\
\hline Nodules & 8 & 14 & 5 & 10.0 & 131 & 18.6 & 32 & 4.6 \\
\hline $\begin{array}{l}\text { Paresis of the } \\
\text { recurrent nerve }\end{array}$ & 0 & 0 & 0 & 0.0 & 7 & 1.0 & 2 & 0.3 \\
\hline Cosmetics & 1 & 2 & 1 & 2.0 & 7 & 1.0 & 3 & 0.4 \\
\hline Pressure symptoms & 39 & 67 & 10 & 20.0 & 520 & 73.7 & 277 & 40.1 \\
\hline Respiratory influence & 2 & 3 & 7 & 14.0 & 19 & 2.7 & 66 & 9.6 \\
\hline Thyrotoxicosis & 7 & 12 & 15 & 30.0 & 6 & 0.8 & 239 & 34.6 \\
\hline Thyroiditis & 0 & 0 & 1 & 2.0 & 1 & 0.1 & 1 & 0.1 \\
\hline Parathyroid disease & 0 & 0 & 7 & 14.0 & 11 & 1.6 & 49 & 7.1 \\
\hline Other & 0 & 0 & 2 & 4.0 & 3 & 0.4 & 10 & 1.4 \\
\hline Missing & 1 & 2 & 2 & 4.0 & 1 & 0.1 & 11 & 1.6 \\
\hline
\end{tabular}

FNA, Fine-needle aspiration.

Table 7. TNM in patients with malignant histology, subgrouped by FNA (benign/without)

\begin{tabular}{|c|c|c|c|c|c|c|c|c|c|c|c|c|c|c|c|c|c|c|}
\hline & \multicolumn{2}{|l|}{$\mathrm{T} 1$} & \multicolumn{2}{|l|}{$\mathrm{T} 2$} & \multicolumn{2}{|l|}{$\mathrm{T}^{\mathrm{a}}$} & \multicolumn{2}{|l|}{$\mathrm{T} 4^{\mathrm{a}}$} & \multicolumn{2}{|l|}{ No } & \multicolumn{2}{|l|}{$\mathrm{N} 1$} & \multicolumn{2}{|l|}{ M0 } & \multicolumn{2}{|l|}{ M1 } & \multicolumn{2}{|c|}{$\begin{array}{l}\text { Not } \\
\text { classified }\end{array}$} \\
\hline & $\mathrm{B}$ & $\mathrm{W} / \mathrm{O}$ & $\mathrm{B}$ & $\mathrm{W} / \mathrm{O}$ & $\mathrm{B}$ & $\mathrm{W} / \mathrm{O}$ & $\mathrm{B}$ & $\mathrm{W} / \mathrm{O}$ & $\mathrm{B}$ & $\mathrm{W} / \mathrm{O}$ & $\mathrm{B}$ & $\mathrm{W} / \mathrm{O}$ & $\mathrm{B}$ & $\mathrm{W} / \mathrm{O}$ & B & $\mathrm{W} / \mathrm{O}$ & B & $\mathrm{W} / \mathrm{O}$ \\
\hline Papillary carcinoma & 31 & 25 & 7 & 4 & 6 & 1 & 0 & 0 & 42 & 25 & 2 & 5 & 44 & 29 & 0 & 1 & 2 & 1 \\
\hline Follicular carcinoma & 1 & 1 & 1 & 1 & 3 & 2 & 2 & 2 & 7 & 6 & 0 & 0 & 7 & 6 & 0 & 0 & 0 & 1 \\
\hline Medullary carcinoma & 1 & 2 & 1 & 0 & 0 & 0 & 0 & 0 & 2 & 2 & 0 & 0 & 2 & 2 & 0 & 0 & 0 & 0 \\
\hline Undifferentiated carcinoma & 0 & 0 & 0 & 0 & 0 & 0 & 0 & 3 & 0 & 2 & 0 & 1 & 0 & 1 & 0 & 2 & 1 & 0 \\
\hline Other malignant histology & 0 & 0 & 0 & 0 & 0 & 0 & 0 & 0 & 0 & 0 & 0 & 0 & 0 & 0 & 0 & 0 & 2 & 7 \\
\hline Total with given TNM stage in FNA group & 33 & 28 & 9 & 5 & 9 & 3 & 2 & 5 & 51 & 35 & 2 & 6 & 53 & 38 & 0 & 3 & 5 & 9 \\
\hline Total as $\%$ of FNA group & 56.9 & 56.0 & 15.5 & 10.0 & 15.5 & 6.0 & 3.4 & 10.0 & 87.9 & 70.0 & 3.4 & 12.0 & 91.4 & 76.0 & 0.0 & 6.0 & 8.6 & 18.0 \\
\hline
\end{tabular}

reports, small studies, and a few reviews have been reported in the past [21-23].

Although no statistical difference could be determined when comparing the group of benign FNA $(n=764)$ with the total thyroid cancer population $(n=3703)$, it was remarkable that more papillary carcinomas (79.3\%) were found in the group with benign FNA. This was likely due to PMC, which inaccurate FNA may have trouble detecting $[24,25]$. The improvement in the overall mortality of thyroid carcinoma can be attributed to an increased number of detected low-mortality PMC. As seen with prostate cancer, it is also possible that an increasing share of thy- roid cancer patients will die with, rather than from, the disease [1]. The group without FNA performed were distributed similarly to the total thyroid cancer population, but the high number of undifferentiated carcinomas (6.0\%) was noteworthy due to the severe prognosis in these cases.

It is advisable to suspect malignancy in thyroid nodules in cases of stridor, fast-growing nodules, rigid and immobile nodules, and paresis of the recurrent laryngeal nerve [26]. Additionally, associations between Hashimoto's thyroiditis and papillary thyroid carcinoma have been found [27]. Indicators of thyroid malignancy are 
Table 8. Stage in patients with malignant histology $(n=108)$, subgrouped by FNA

\begin{tabular}{|c|c|c|c|c|c|c|c|c|c|c|}
\hline & \multicolumn{2}{|l|}{ I } & \multicolumn{2}{|l|}{ II } & \multicolumn{2}{|l|}{ III } & \multicolumn{2}{|l|}{ IV } & \multicolumn{2}{|c|}{$\begin{array}{l}\text { Not } \\
\text { classified }\end{array}$} \\
\hline & $\mathrm{B}$ & $\mathrm{W} / \mathrm{O}$ & $\mathrm{B}$ & $\mathrm{W} / \mathrm{O}$ & $\mathrm{B}$ & $\mathrm{W} / \mathrm{O}$ & $\mathrm{B}$ & $\mathrm{W} / \mathrm{O}$ & $\mathrm{B}$ & $\mathrm{W} / \mathrm{O}$ \\
\hline Papillary carcinoma & 38 & 22 & 3 & 4 & 1 & 2 & 2 & 2 & 2 & 1 \\
\hline Follicular carcinoma & 5 & 3 & 0 & 0 & 1 & 1 & 1 & 2 & 0 & 1 \\
\hline Medullary carcinoma & 1 & 2 & 1 & 0 & 0 & 0 & 0 & 0 & 0 & 0 \\
\hline Sum & 44 & 27 & 4 & 4 & 2 & 3 & 3 & 7 & 5 & 9 \\
\hline FNA group with respective stage, $\%$ & 75.9 & 54.0 & 6.9 & 8.0 & 3.4 & 6.0 & 5.2 & 14.0 & 8.6 & 18.0 \\
\hline
\end{tabular}

B, benign FNA $(n=58)$; W/O, without FNA $(n=50)$.

valuable as they help prevent delayed diagnosis and the worsened outcome as a result hereof. We evaluated a broad selection of possible predictive factors and discovered solitary solid tumour on ultrasound to be a predictive factor tested with both multiple logistic regression and $\chi^{2}$ test. Thyrotoxicosis (in this case medically treated) was also a significant predictive factor for malignancy. Compared to the guidelines for ultrasound malignancy risk stratification in the EU-TIRADS [28], we compared solid tumour on ultrasound with a composite group of other findings, thus not taking microcalcifications, "taller-thanwide" shapes, and irregular margins into account - all candidate limitations to the study. Additionally, data from this study were probably not comparable to studies from countries with a longer history of iodine sufficiency, as Denmark has a high occurrence of multinodular goitres, thus more benign nodules and consequently a lower risk of malignant nodule histology. When endocrinologists attend to the patients first, those referred for thyroid surgery constitute a selected cohort, whereas data from an unselected cohort would have shown very different characteristics. Correlations detected in this study were extremely dependant on descriptions of ultrasound and cytological definitions. As an example, from 2000 to 2005 Rigshospitalet employed thyroperoxidase immunostaining of the solitary solid thyroid nodule when distinguishing between benign and malignant tumour cells in coarseneedle biopsy and it is currently used in FNA $[29,30]$.

In conclusion, in a Danish population of moderately low iodine insufficiency until the year 2000 and thus a low a priori likelihood for cancer in thyroid nodules, our finding of a risk of malignancy of 7.6 and $6.8 \%$ (in patients with benign FNA and without FNA, respectively) indi-
Table 9. Outcome in patients with malignant histology $\geq \mathrm{T} 2(n=33)$

\begin{tabular}{lrrrrr}
\hline & T2 & T3 & T4 & Total & $\%$ \\
\hline Alive with no disease & 12 & 9 & 2 & 23 & 76.7 \\
Reoperation & 2 & 2 & 1 & 5 & 16.7 \\
Recurrence & 0 & 1 & 0 & 1 & 3.3 \\
Dead & 0 & 0 & 4 & 4 & 12.1 \\
\hline
\end{tabular}

cates that in cases with a solitary solid tumour on ultrasound, risk of malignancy should be considered, even with benign FNA. Patients with thyroid malignancy classified as T2-4 $(2.2 \%, n=33)$ within both groups were found, and 9 of these experienced reoperation, recurrence, or death by thyroid cancer, making it essential to identify and adequately treat these cases.

\section{Acknowledgements}

The research salary of U.F.-R. was sponsored by NovoNordisk Research Fund. S.B.G. was sponsored by Agnes and Knut Mørks Fund.

\section{Statement of Ethics}

The authors have no ethical conflicts to disclose.

\section{Disclosure Statement}

The authors have no conflicts of interest to declare. 


\section{References}

1 Blomberg M, Feldt-Rasmussen U, Andersen KK, Kjaer SK. Thyroid cancer in Denmark 1943-2008, before and after iodine supplementation. Int J Cancer. 2012 Nov;131(10): 2360-6.

2 Mirian C, Grønhøj C, Jensen DH, Jakobsen KK, Karnov K, Jensen JS, et al. Trends in thyroid cancer: retrospective analysis of incidence and survival in Denmark 1980-2014. Cancer Epidemiol. 2018 Aug;55(March):817.

3 Pellegriti G, Frasca F, Regalbuto C, Squatrito $\mathrm{S}$, Vigneri R. Worldwide increasing incidence of thyroid cancer: update on epidemiology and risk factors. J Cancer Epidemiol. 2013; 2013:965212.

4 Londero SC, Krogdahl A, Bastholt L, Overgaard J, Pedersen $\mathrm{HB}$, Hahn $\mathrm{CH}$, et al. Papillary thyroid carcinoma in Denmark, 19962008: outcome and evaluation of established prognostic scoring systems in a prospective national cohort. Thyroid. 2015 Jan;25(1):7884.

5 Sorensen JR, Johansen J, Gano L, Sørensen JA, Larsen SR, Andersen PB, et al. A “package solution" fast track program can reduce the diagnostic waiting time in head and neck cancer. Eur Arch Otorhinolaryngol. 2014 May; 271(5):1163-70.

6 Egset AV, Holm C, Larsen SR, Nielsen SH, Bach J, Helweg-Larsen JP, et al. Risk of malignancy in fine-needle aspiration biopsy in patients with thyroid nodules. Dan Med J. 2017 Feb;64(2):1-4.

7 Tandon S, Shahab R, Benton JI, Ghosh SK, Sheard J, Jones TM. Fine-needle aspiration cytology in a regional head and neck cancer center: comparison with a systematic review and meta-analysis. Head Neck. 2008 Sep 30(9):1246-52.

8 Haugen BR, Alexander EK, Bible KC, Doherty GM, Mandel SJ, Nikiforov YE, et al. 2015 American Thyroid Association Management Guidelines for Adult Patients with Thyroid Nodules and Differentiated Thyroid Cancer: The American Thyroid Association Guidelines Task Force on Thyroid Nodules and Differentiated Thyroid Cancer. Thyroid. 2016 Jan;26(1):1-133.

9 Yamamoto Y, Maeda T, Izumi K, Otsuka H. Occult papillary carcinoma of the thyroid. A study of 408 autopsy cases. Cancer. 1990;65 1173-79.
10 Harach HR, Sariola T. Occult Papillary Carcinoma. 1984;50.

11 Miyauchi A, Ito Y, Oda H. Insights into the Management of Papillary Microcarcinoma of the Thyroid. Thyroid. 2018 Jan;28(1):23-31.

12 Leboulleux S, Tuttle RM, Pacini F, Schlumberger M. Papillary thyroid microcarcinoma: time to shift from surgery to active surveillance? Lancet Diabetes Endocrinol. 2016 Nov; 4(11):933-42

13 Tee YY, Lowe AJ, Brand CA, Judson RT. Fineneedle aspiration may miss a third of all malignancy in palpable thyroid nodules: a comprehensive literature review. Ann Surg. 2007 Nov;246(5):714-20.

14 Orlandi A, Puscar A, Capriata E, Fideleff $\mathrm{H}$. Repeated fine-needle aspiration of the thyroid in benign nodular thyroid disease: critical evaluation of long-term follow-up. Thyroid. 2005 Mar;15(3):274-8.

15 Oertel YC, Miyahara-Felipe L, Mendoza MG, $\mathrm{Yu}$ K. Value of repeated fine needle aspirations of the thyroid: an analysis of over ten thousand FNAs. Thyroid. 2007 Nov;17(11): 1061-6.

16 Illouz F, Rodien P, Saint-André JP, Triau S, Laboureau-Soares S, Dubois S, et al. Usefulness of repeated fine-needle cytology in the follow-up of non-operated thyroid nodules. Eur J Endocrinol. 2007 Mar;156(3):303-8.

17 Kuru B, Gulcelik NE, Gulcelik MA, Dincer H. The false-negative rate of fine-needle aspiration cytology for diagnosing thyroid carcino$\mathrm{ma}$ in thyroid nodules. Langenbecks Arch Surg. 2010 Feb;395(2):127-32.

18 Pinchot SN, Al-Wagih H, Schaefer S, Sippel R, Chen H. Accuracy of fine-needle aspiration biopsy for predicting neoplasm or carcinoma in thyroid nodules $4 \mathrm{~cm}$ or larger. Arch Surg. 2009 Jul;144(7):649-55.

19 Wharry LI, McCoy KL, Stang MT, Armstrong MJ, LeBeau SO, Tublin ME, et al. Thyroid nodules $(\geq 4 \mathrm{~cm})$ : can ultrasound and cytology reliably exclude cancer? World J Surg. 2014 Mar;38(3):614-21.

20 Nam SJ, Kwak JY, Moon HJ, Yoon JH, Kim E, Koo JS. Large $(\geq 3 \mathrm{~cm})$ thyroid nodules with benign cytology: Can Thyroid Imaging Reporting and Data System(TIRADS) help predict false-negative cytology? PLoS One. 2017 Oct;12(10):e0186242.
21 Tam AA, Kaya C, Kılıç FB, Ersoy R, Çakır B. Thyroid nodules and thyroid cancer in Graves' disease. Arq Bras Endocrinol Metabol. 2014 Dec;58(9):933-8.

22 Rees DO, Anthony VA, Jones K, Stephens JW. Follicular variant of papillary thyroid carcinoma: an unusual cause of thyrotoxicosis. BMJCaseRep.2015May;2015:bcr2014207091.

23 Folkestad L, Brandt F, Brix T, Vogsen M, Bastholt L, Grupe P, et al. Total Thyroidectomy for Thyroid Cancer Followed by Thyroid Storm due to Thyrotropin Receptor Antibody Stimulation of Metastatic Thyroid Tissue. Eur Thyroid J. 2017 Sep;6(5):276-80.

24 Rossing M, Nygaard B, Nielsen FC, Bennedbæk FN. High prevalence of papillary thyroid microcarcinoma in danish patients: a prospective study of 854 consecutive patients with a cold thyroid nodule undergoing fine-needle aspiration. Eur Thyroid J. 2012 Jul;1(2):110-7.

25 Londero SC, Krogdahl A, Bastholt L, Overgaard J, Trolle W, Pedersen HB, et al.; Danish Thyroid Cancer Group. Papillary thyroid microcarcinoma in Denmark 1996-2008: a national study of epidemiology and clinical significance. Thyroid. 2013 Sep;23(9):1159-64.

26 Mitchell AL, Gandhi A, Scott-Coombes D, Perros P. Management of thyroid cancer: United Kingdom National Multidisciplinary Guidelines. J Laryngol Otol. 2016 May;130 S2:S150-60.

27 Paiva CR De, Grønhøj C, Feldt-rasmussen U, von Buchwald C. Association between Hashimoto's Thyroiditis and Thyroid Cancer in 64,628 Patients. Front Oncol. 2017 Apr;7:53.

28 Russ G, Bonnema SJ, Erdogan MF, Durante C, Ngu R, Leenhardt L. European Thyroid Association Guidelines for Ultrasound Malignancy Risk Stratification of Thyroid Nodules in Adults: the EU-TIRADS. Eur Thyroid J. 2017 Sep;6(5):225-37

29 Christensen L, Blichert-toft M, Brandt M, Lange M, Sneppen B, Feldt-rasmussen U, et al. Thyroperoxidase (TPO) immunostaining of the solitary cold thyroid nodule. Clin Endocrinol (Oxf). 2000 Aug;53(2):161-9.

30 Yousaf U, Christensen LH, Rasmussen $\AA$ K, Jensen F, Mollerup CL, Feldt-Rasmussen U. Immunohistochemical staining for thyroid peroxidase (TPO) of needle core biopsies in the diagnosis of scintigraphically cold thyroid nodules. Clin Endocrinol (Oxf). 2008 Jun; 68(6):996-1001. 